\title{
Effects of Pressure, Temperature, and Concentration on the Viscosity of Aqueous Ammonium Bromide Solution
}

\author{
Yukihiro Yoshimura*, Seiji Sawamura, and Yoshihiro Taniguchi \\ Department of Chemistry, Faculty of Science and Engineering, Ritsumeikan University, Kusatsu, \\ Shiga, 525-77, Japan. \\ Z. Naturforsch. 50a, 316-322 (1995); received December 14, 1994 \\ Dedicated to Prof. Hitoshi Ohtaki on the occasion of his 60th birthday
}

\begin{abstract}
The viscosity of aqueous ammonium bromide solutions is measured at $0.1-1.0 \mathrm{~mol} \mathrm{~kg}^{-1}, 278.2-$ $323.2 \mathrm{~K}$, and $0.1-375 \mathrm{MPa}$, using a high-pressure rolling-ball viscometer. The activation energy $\left(E_{\mathrm{v}}\right)$ for viscous flow and Jones-Dole's $B$ coefficient are estimated. $E_{\mathrm{v}}$ against pressure yields a concave curve with a minimum and $B$ yields a convex one with a maximum. These phenomena are attributed to pressure, temperature, and concentration effects on the water-structure.
\end{abstract}

Key words: Viscosity, High pressure, Ammonium bromide, Activation energy, Jones-Dole's $B$ coefficient

\section{Introduction}

It is well known that the viscosity curve at low temperature of water against pressure exhibits a minimum, e.g. at $100 \mathrm{MPa}$ for an isothermal curve at $283 \mathrm{~K}$ [1]. The reduction of the viscosity with increasing pressure up to the minimum has been ascribed to breaking of the bulky water-structure by compression [2] and the increase of the viscosity after the minimum has been reached to stuffing. The minimum shifts to lower pressure with increasing temperature and disappears at ca. $310 \mathrm{~K}$ because of the breaking of the hydrogen-bonding [1].

Another type of reduction of the viscosity of water is known to be caused by addition of an electrolyte whose Jones-Dole's $B$ coefficient is negative, suggesting breaking of water-structure at atmospheric pressure [3]. A typical electrolyte showing this effect is ammonium bromide $\left(\mathrm{NH}_{4} \mathrm{Br}\right)$. We are interested in the viscosity phenomena of aqueous $\mathrm{NH}_{4} \mathrm{Br}$ solutions at high pressure where the water structure is broken. In the present work we have measured the viscosity of aqueous $\mathrm{NH}_{4} \mathrm{Br}$ solutions as a function of pressure, temperature, and concentration. The results are compared with those of $\mathrm{NaCl}$ [4], whose $B$ coefficients is slightly positive.

\footnotetext{
* Present address: Department of Chemistry, National Defense Academy, Hashirimizu, Yokosuka, Kanagawa, 239, Japan.

Reprint requests to Prof. S. Sawamura.
}

To estimate the viscosity, the density of the solution is needed [4]. Therefore the high-pressure density of the solution was also measured.

\section{Experimental Section}

$\mathrm{NH}_{4} \mathrm{Br}$ purchased from Nakarai Tesque, Inc. (extra pure grade) was recrystallized twice from water and dried in a vacuum desicator over $\mathrm{P}_{2} \mathrm{O}_{5}$. The purity of the salts was checked to be better than $99.8 \%$ by titration with $0.1 \mathrm{~mol} \mathrm{dm}^{-3} \mathrm{AgNO}_{3}$. The concentrations of the sample solutions were $0.100,0.300,0.500$, 0.700 , and $1.000( \pm 0.0002) \mathrm{mol} \mathrm{kg}^{-1}$. They were passed through a membrane filter $(d=25 \mathrm{~mm}$, pore size $0.1 \mu \mathrm{m}$ ), to remove dust, and then put into viscometers or pycnometers.

The viscosity at $0.1 \mathrm{MPa}$ was measured using an Ubbelohde-type viscometer and that at high pressure was done using a rolling-ball type viscometer designed by us [6]. The viscosity, $\eta$, was estimated from the rolling time, $t$ :

$$
\eta=K\left(d_{\mathrm{b}}-d\right) t,
$$

where $K$ is a constant for the equipment and $d_{\mathrm{b}}$ and $d$ are the density of the ball and solution, respectively. The density of the solution at $0.1 \mathrm{MPa}$ was measured using an Ostwald's pycnometer $\left(25 \mathrm{~cm}^{3}\right)$. To estimate the high-pressure density, the compression $k$, defined by

$$
\left.k=\left(d-d_{0}\right) / d\right)
$$


Table 1. Compression of aqueous $\mathrm{NH}_{4} \mathrm{Br}$ solution.

\begin{tabular}{|c|c|c|c|c|c|c|}
\hline \multirow[t]{2}{*}{$p / \mathrm{MPa}$} & \multicolumn{6}{|c|}{$T / \mathrm{K}$} \\
\hline & 278.2 & 283.2 & 288.2 & 298.2 & 313.2 & 323.2 \\
\hline \multicolumn{7}{|c|}{$0.100 \mathrm{~mol} \mathrm{~kg}^{-1}$} \\
\hline 50 & 0.0220 & 0.0217 & 0.0221 & 0.0205 & 0.0195 & 0.0200 \\
\hline 100 & 0.0412 & 0.0401 & 0.0396 & 0.0388 & 0.0365 & 0.0372 \\
\hline 150 & 0.0577 & 0.0572 & 0.0553 & 0.0537 & 0.0510 & 0.0510 \\
\hline 200 & 0.0720 & 0.0707 & 0.0696 & 0.0679 & 0.0648 & 0.0656 \\
\hline 250 & 0.0854 & 0.0844 & 0.0833 & 0.0801 & 0.0770 & 0.0772 \\
\hline 300 & 0.0975 & 0.0964 & 0.0962 & 0.0912 & 0.0913 & 0.0887 \\
\hline \multicolumn{7}{|c|}{$0.300 \mathrm{~mol} \mathrm{~kg}^{-1}$} \\
\hline 50 & 0.0237 & 0.0222 & 0.0209 & 0.0204 & 0.0185 & 0.0177 \\
\hline 100 & 0.0403 & 0.0396 & 0.0395 & 0.0387 & 0.0370 & 0.0357 \\
\hline 150 & 0.0573 & 0.0553 & 0.0544 & 0.0521 & 0.0507 & 0.0490 \\
\hline 200 & 0.0712 & 0.0699 & 0.0691 & 0.0680 & 0.0671 & 0.0651 \\
\hline 250 & 0.0839 & 0.0828 & 0.0817 & 0.0795 & 0.0761 & 0.0759 \\
\hline 300 & 0.0983 & 0.0963 & 0.0952 & 0.0934 & 0.0899 & 0.0860 \\
\hline \multicolumn{7}{|c|}{$0.500 \mathrm{~mol} \mathrm{~kg}^{-1}$} \\
\hline 50 & 0.0243 & 0.0222 & 0.0203 & 0.0201 & 0.0179 & 0.0166 \\
\hline 100 & 0.0399 & 0.0392 & 0.0392 & 0.0382 & 0.0370 & 0.0348 \\
\hline 150 & 0.0570 & 0.0543 & 0.0537 & 0.0510 & 0.0502 & 0.0479 \\
\hline 200 & 0.0706 & 0.0692 & 0.0685 & 0.0674 & 0.0674 & 0.0643 \\
\hline 250 & 0.0829 & 0.0816 & 0.0806 & 0.0786 & 0.0752 & 0.0748 \\
\hline 300 & 0.0981 & 0.0957 & 0.0942 & 0.0935 & 0.0875 & 0.0869 \\
\hline \multicolumn{7}{|c|}{$0.700 \mathrm{~mol} \mathrm{~kg}^{-1}$} \\
\hline 50 & 0.0235 & 0.0218 & 0.0202 & 0.0197 & 0.0177 & 0.0168 \\
\hline 100 & 0.0397 & 0.0390 & 0.0386 & 0.0376 & 0.0362 & 0.0345 \\
\hline 150 & 0.0566 & 0.0541 & 0.0533 & 0.0505 & 0.0495 & 0.0476 \\
\hline 200 & 0.0702 & 0.0686 & 0.0679 & 0.0662 & 0.0657 & 0.0633 \\
\hline 250 & 0.0823 & 0.0809 & 0.0799 & 0.0776 & 0.0742 & 0.0738 \\
\hline 300 & 0.0967 & 0.0944 & 0.0931 & 0.0914 & 0.0862 & 0.0853 \\
\hline \multicolumn{7}{|c|}{$1.000 \mathrm{~mol} \mathrm{~kg}^{-1}$} \\
\hline 50 & 0.0219 & 0.0210 & 0.0202 & 0.0190 & 0.0184 & 0.0182 \\
\hline 100 & 0.0404 & 0.0340 & 0.0376 & 0.0356 & 0.0345 & 0.0342 \\
\hline 150 & 0.0563 & 0.0546 & 0.0529 & 0.0503 & 0.0488 & 0.0483 \\
\hline 200 & 0.0704 & 0.0684 & 0.0666 & 0.0635 & 0.0618 & 0.0609 \\
\hline 250 & 0.0829 & 0.0808 & 0.0790 & 0.0754 & 0.0735 & 0.0724 \\
\hline 300 & 0.0943 & 0.0920 & 0.0903 & 0.0864 & 0.0843 & 0.0829 \\
\hline
\end{tabular}

where $d_{0}$ is the density of the solution at $0.1 \mathrm{MPa}$, was measured using an Adams-type piezometer [7]. The detail for these measurements were previously described $[4-6,8]$.

\section{Results and Discussion}

\subsection{Density of Aqueous $\mathrm{NH}_{4} \mathrm{Br}$ Solution}

The obtained compression of the solution is listed in Table 1. It is well known that the modified Tait's equation

$$
k=E \log _{10}[(F+p) /(F+0.1)],
$$

Table 2. Density at $0.1 \mathrm{MPa}$ and parameters of modified Tait's equation.

\begin{tabular}{|c|c|c|c|c|}
\hline$\frac{T}{\mathrm{~K}}$ & $\frac{m}{\mathrm{~mol} \mathrm{~kg}^{-1}}$ & $\frac{d_{0}}{\mathrm{~g} \mathrm{~cm}^{-3}}$ & $E$ & $\frac{F}{\mathrm{MPa}}$ \\
\hline 278.2 & $\begin{array}{l}0.100 \\
0.300 \\
0.500 \\
0.700 \\
1.000\end{array}$ & $\begin{array}{l}1.00548 \\
1.01649 \\
1.02737 \\
1.03811 \\
1.05399\end{array}$ & $\begin{array}{l}0.3031 \\
0.2971 \\
0.2914 \\
0.2856 \\
0.2773\end{array}$ & $\begin{array}{l}273.8 \\
268.8 \\
263.9 \\
258.9 \\
251.5\end{array}$ \\
\hline 283.2 & $\begin{array}{l}0.100 \\
0.300 \\
0.500 \\
0.700 \\
1.000\end{array}$ & $\begin{array}{l}1.00514 \\
1.01604 \\
1.02682 \\
1.03746 \\
1.05323\end{array}$ & $\begin{array}{l}0.3135 \\
0.3065 \\
0.2999 \\
0.2929 \\
0.2841\end{array}$ & $\begin{array}{l}291.5 \\
286.7 \\
281.9 \\
277.2 \\
269.9\end{array}$ \\
\hline 288.2 & $\begin{array}{l}0.100 \\
0.300 \\
0.500 \\
0.700 \\
1.000\end{array}$ & $\begin{array}{l}1.00455 \\
1.01539 \\
1.02608 \\
1.03663 \\
1.05221\end{array}$ & $\begin{array}{l}0.3201 \\
0.3128 \\
0.3061 \\
0.2993 \\
0.2894\end{array}$ & $\begin{array}{l}305.7 \\
301.4 \\
297.1 \\
292.8 \\
286.3\end{array}$ \\
\hline 298.2 & $\begin{array}{l}0.100 \\
0.300 \\
0.500 \\
0.700 \\
1.000\end{array}$ & $\begin{array}{l}1.00246 \\
1.01321 \\
1.02379 \\
1.03421 \\
1.04956\end{array}$ & $\begin{array}{l}0.3243 \\
0.3203 \\
0.3143 \\
0.3078 \\
0.2984\end{array}$ & $\begin{array}{l}323.0 \\
322.4 \\
319.3 \\
316.2 \\
311.5\end{array}$ \\
\hline 313.2 & $\begin{array}{l}0.100 \\
0.300 \\
0.500 \\
0.700 \\
1.000\end{array}$ & $\begin{array}{l}0.99768 \\
1.00831 \\
1.01876 \\
1.02902 \\
1.04400\end{array}$ & $\begin{array}{l}0.3203 \\
0.3156 \\
0.3096 \\
0.3042 \\
0.2957\end{array}$ & $\begin{array}{l}330.0 \\
328.6 \\
326.1 \\
323.7 \\
320.1\end{array}$ \\
\hline 323.2 & $\begin{array}{l}0.100 \\
0.300 \\
0.500 \\
0.700 \\
1.000\end{array}$ & $\begin{array}{l}0.99357 \\
1.00409 \\
1.01449 \\
1.02477 \\
1.03980\end{array}$ & $\begin{array}{l}0.3187 \\
0.3112 \\
0.3025 \\
0.2941 \\
0.2816\end{array}$ & $\begin{array}{l}331.8 \\
327.9 \\
322.8 \\
317.7 \\
310.1\end{array}$ \\
\hline
\end{tabular}

where $E$ and $F$ are constants and $p$ is the pressure (MPa), is applicable to many compression data of liquids, such as organic solvents and water, as a function of pressure [9]. Our compression data in Table 1 are fitted to this equation, and $E$ and $F$ values are obtained as listed in Table 2. To estimate the highpressure density, we did not use the compression data in Table 1 but those calculated from (3), using the $E$ and $F$ values in Table 2 . The densities at $0.1 \mathrm{MPa}$ are also listed in Table 2.

\subsection{Pressure Dependence of the Viscosity}

The viscosities are listed in Table 3 and plotted in Figure 1. The solid curves in Fig. 1 are fitting curves.

$$
\eta=f_{0}+f_{1} p+f_{2} p^{2},
$$

where $f_{0}, f_{1}$, and $f_{2}$ are coefficients and the numerical values are tabulated in Table 4. The deviation of the 
Table 3. Viscosity $\left(\eta / \mathrm{mPa}\right.$ s) of aqueous $\mathrm{NH}_{4} \mathrm{Br}$ solution

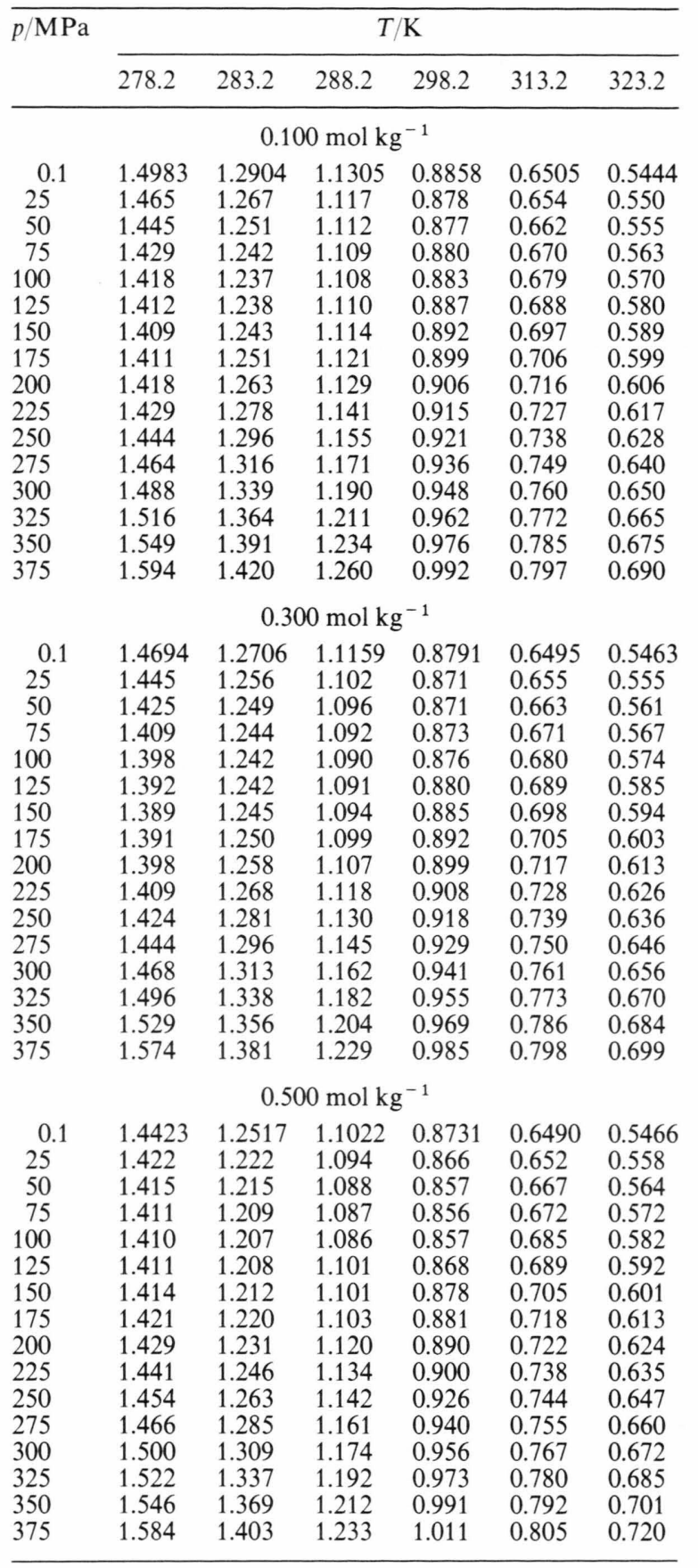

dots from the curves is at most $\pm 1 \%$. The curves at zero concentration are cited from [1]. The viscosity curve of water at zero concentration at lower temperatures than $298.2 \mathrm{~K}$ shows a minimum in Figure 1. The curve is deformed by addition of $\mathrm{NH}_{4} \mathrm{Br}$, but the
Table 3. Continued.

\begin{tabular}{|c|c|c|c|c|c|c|}
\hline \multirow[t]{2}{*}{$\overline{p / \mathrm{MPa}}$} & \multicolumn{6}{|c|}{$T / \mathrm{K}$} \\
\hline & 278.2 & 283.2 & 288.2 & 298.2 & 313.2 & 323.2 \\
\hline \multicolumn{7}{|c|}{$0.700 \mathrm{~mol} \mathrm{~kg}^{-1}$} \\
\hline 0.1 & 1.4168 & 1.2336 & 1.0893 & 0.8678 & 0.6488 & 0.5474 \\
\hline 25 & 1.396 & 1.210 & 1.082 & 0.857 & 0.653 & 0.559 \\
\hline 50 & 1.394 & 1.201 & 1.074 & 0.851 & 0.657 & 0.570 \\
\hline 75 & 1.396 & 1.197 & 1.071 & 0.848 & 0.662 & 0.580 \\
\hline 100 & 1.399 & 1.198 & 1.070 & 0.849 & 0.675 & 0.590 \\
\hline 125 & 1.400 & 1.204 & 1.074 & 0.852 & 0.679 & 0.600 \\
\hline 150 & 1.416 & 1.215 & 1.082 & 0.859 & 0.695 & 0.610 \\
\hline 175 & 1.436 & 1.232 & 1.094 & 0.868 & 0.708 & 0.620 \\
\hline 200 & 1.451 & 1.253 & 1.109 & 0.881 & 0.712 & 0.631 \\
\hline 225 & 1.460 & 1.280 & 1.128 & 0.897 & 0.728 & 0.641 \\
\hline 250 & 1.490 & - & 1.151 & 0.916 & 0.734 & 0.655 \\
\hline 275 & 1.515 & - & 1.178 & 0.938 & 0.7 & .665 \\
\hline 300 & 1.533 & - & - & 0.963 & 0.757 & 0.680 \\
\hline 325 & 1.575 & - & - & 0.992 & 0.770 & 0.695 \\
\hline 350 & 1.610 & - & - & - & 0.782 & 0.712 \\
\hline 375 & 1.635 & - & - & - & 0.795 & 0.730 \\
\hline \multicolumn{7}{|c|}{$1.000 \mathrm{~mol} \mathrm{~kg}^{-1}$} \\
\hline 0.1 & 1.3861 & 1.2125 & 1.0716 & 0.8616 & 0.6505 & 0.5497 \\
\hline 25 & 1.380 & 1.190 & 1.064 & 0.851 & 0.652 & 0.564 \\
\hline 50 & 1.373 & 1.181 & 1.056 & 0.845 & 0.667 & 0.572 \\
\hline 75 & 1.384 & - & 1.053 & 0.842 & 0.672 & 0.582 \\
\hline 100 & 1.386 & - & 1.052 & 0.843 & 0.685 & 0.591 \\
\hline 125 & 1.400 & - & 1.056 & 0.846 & 0.689 & 0.603 \\
\hline 150 & 1.424 & - & 1.064 & 0.854 & 0.705 & 0.615 \\
\hline 175 & 1.434 & - & 1.084 & 0.862 & 0.718 & 0.626 \\
\hline 200 & 1.468 & 1.260 & 1.113 & 0.875 & 0.722 & 0.637 \\
\hline 225 & 1.490 & 1.290 & 1.138 & 0.901 & 0.738 & 0.650 \\
\hline 250 & 1.520 & 1.321 & 1.161 & 0.919 & 0.744 & 0.663 \\
\hline 275 & 1.551 & 1.358 & 1.188 & 0.941 & 0.755 & 0.675 \\
\hline 300 & 1.590 & 1.400 & 1.219 & 0.967 & 0.768 & 0.690 \\
\hline 325 & 1.622 & - & 1.254 & 0.996 & 0.780 & 0.705 \\
\hline 350 & 1.650 & - & 1.292 & 1.042 & 0.792 & 0.725 \\
\hline 375 & 1.699 & - & 1.335 & 1.080 & 0.805 & 0.740 \\
\hline
\end{tabular}

minimum is kept even at $1 \mathrm{~mol} \mathrm{~kg}^{-1}$. This means that addition of $\mathrm{NH}_{4} \mathrm{Br}$ up to $1 \mathrm{~mol} \mathrm{~kg}{ }^{-1}$ does not completely break the water structure at $0.1 \mathrm{MPa}$.

\subsection{Temperature Dependence of the Viscosity}

Temperature dependence of the viscosity has been represented by the activation energy, $E_{\mathrm{v}}$, for viscous flow [10] defined by

$$
[\partial \ln \eta / \partial(1 / T)]_{p}=E_{\mathrm{v}} / R .
$$

$E_{\mathrm{v}}$ is an important parameters for the understanding the structure of ionic hydration [11]. $\ln \eta$ vs. $1 / T$ for the solutions at $0.5 \mathrm{~mol} \mathrm{~kg}^{-1}$ is plotted in Fig. 2 as an example. The curves are estimated from Table 4 using (4) and are fitted to the second polynomial of $1 / T$. $E_{\mathrm{v}}$ is estimated from the slope of (5). The pressure dependence of the $E_{\mathrm{v}}$ at $298.2 \mathrm{~K}$ is shown in Figure 3. The 


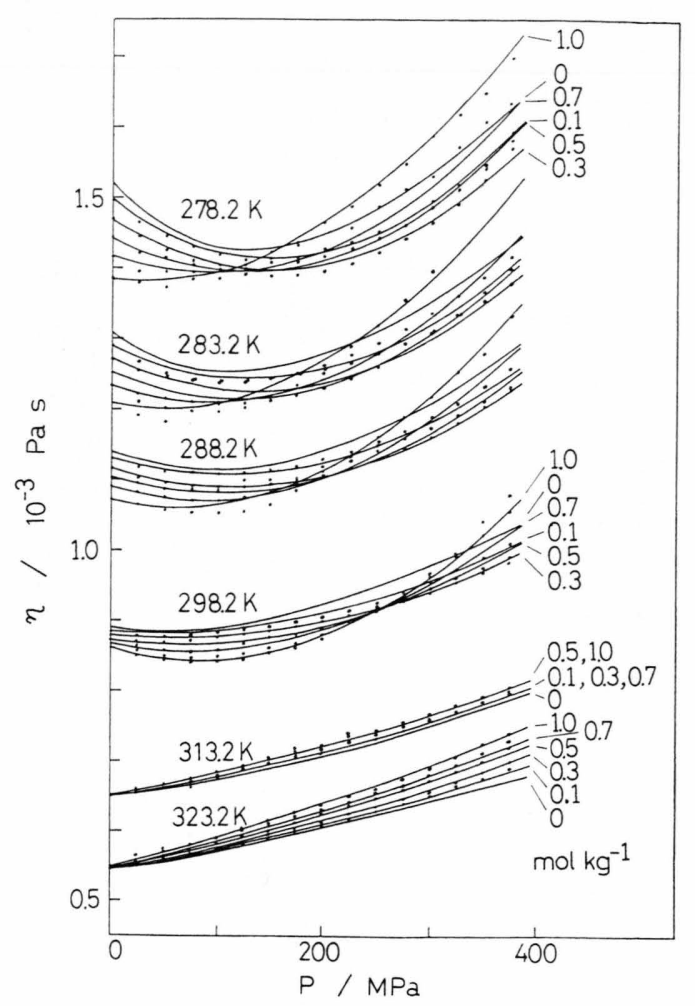

Fig. 1. Pressure dependence of the viscosity for aqueous $\mathrm{NH}_{4} \mathrm{Br}$ solution.

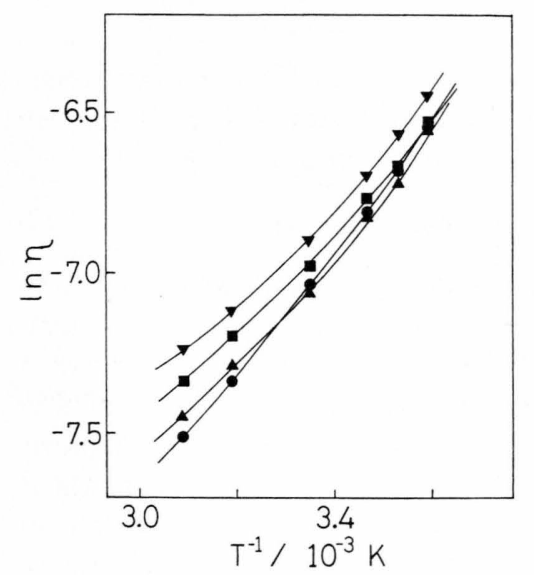

Fig. 2. $\ln \eta$ vs. $1 / T$ for $0.500 \mathrm{~mol} \mathrm{~kg}^{-1} \mathrm{NH}_{4} \mathrm{Br}$ solution. $0.1 \mathrm{MPa}$, «: $100 \mathrm{MPa}$, a: $250 \mathrm{MPa}, \mathbf{v}: 375 \mathrm{MPa}$.
Table 4. Coefficients of $f_{0}, f_{1}$, and $f_{2}$ in (4) for aqueous $\mathrm{NH}_{4} \mathrm{Br}$ solution.

\begin{tabular}{|c|c|c|c|c|}
\hline$T$ & $m$ & $\frac{f_{0}}{10^{-3}}$ & $\frac{f_{1}}{10-12}$ & $\frac{f_{2}}{20-21}$ \\
\hline $\mathrm{K}$ & $\mathrm{mol} \mathrm{kg}^{-1}$ & $10^{-3} \mathrm{~Pa} \mathrm{~s}$ & $10^{-12} \mathrm{~s}$ & $10^{-21} \mathrm{~Pa}^{-1} \mathrm{~s}$ \\
\hline 278.2 & $\begin{array}{l}0.100 \\
0.300 \\
0.500 \\
0.700 \\
1.000\end{array}$ & $\begin{array}{l}1.496 \\
1.468 \\
1.442 \\
1.418 \\
1.383\end{array}$ & $\begin{array}{l}-1.063 \\
-0.936 \\
-0.755 \\
-0.530 \\
-0.096\end{array}$ & $\begin{array}{l}3.555 \\
3.166 \\
3.064 \\
2.900 \\
2.650\end{array}$ \\
\hline 283.2 & $\begin{array}{l}0.100 \\
0.300 \\
0.500 \\
0.700 \\
1.000\end{array}$ & $\begin{array}{l}1.289 \\
1.271 \\
1.251 \\
1.232 \\
1.208\end{array}$ & $\begin{array}{l}-0.695 \\
-0.708 \\
-0.636 \\
-0.504 \\
-0.244\end{array}$ & $\begin{array}{l}2.964 \\
2.701 \\
2.751 \\
2.802 \\
2.802\end{array}$ \\
\hline 288.2 & $\begin{array}{l}0.100 \\
0.300 \\
0.500 \\
0.700 \\
1.000\end{array}$ & $\begin{array}{l}1.131 \\
1.116 \\
1.102 \\
1.088 \\
1.070\end{array}$ & $\begin{array}{l}-0.434 \\
-0.455 \\
-0.418 \\
-0.430 \\
-0.325\end{array}$ & $\begin{array}{l}2.021 \\
2.015 \\
2.120 \\
2.522 \\
2.766\end{array}$ \\
\hline 298.2 & $\begin{array}{l}0.100 \\
0.300 \\
0.500 \\
0.700 \\
1.000\end{array}$ & $\begin{array}{l}0.885 \\
0.878 \\
0.872 \\
0.867 \\
0.860\end{array}$ & $\begin{array}{l}-0.091 \\
-0.119 \\
-0.184 \\
-0.273 \\
-0.402\end{array}$ & $\begin{array}{l}1.104 \\
1.102 \\
1.425 \\
1.860 \\
2.477\end{array}$ \\
\hline 313.2 & $\begin{array}{l}0.100 \\
0.300 \\
0.500 \\
0.700 \\
1.000\end{array}$ & $\begin{array}{l}0.651 \\
0.650 \\
0.649 \\
0.649 \\
0.651\end{array}$ & $\begin{array}{l}0.221 \\
0.240 \\
0.272 \\
0.297 \\
0.296\end{array}$ & $\begin{array}{l}0.391 \\
0.366 \\
0.311 \\
0.259 \\
0.297\end{array}$ \\
\hline 323.2 & $\begin{array}{l}0.100 \\
0.300 \\
0.500 \\
0.700 \\
1.000\end{array}$ & $\begin{array}{l}0.544 \\
0.546 \\
0.547 \\
0.547 \\
0.550\end{array}$ & $\begin{array}{l}0.267 \\
0.274 \\
0.306 \\
0.341 \\
0.387\end{array}$ & $\begin{array}{l}0.281 \\
0.350 \\
0.349 \\
0.335 \\
0.308\end{array}$ \\
\hline
\end{tabular}

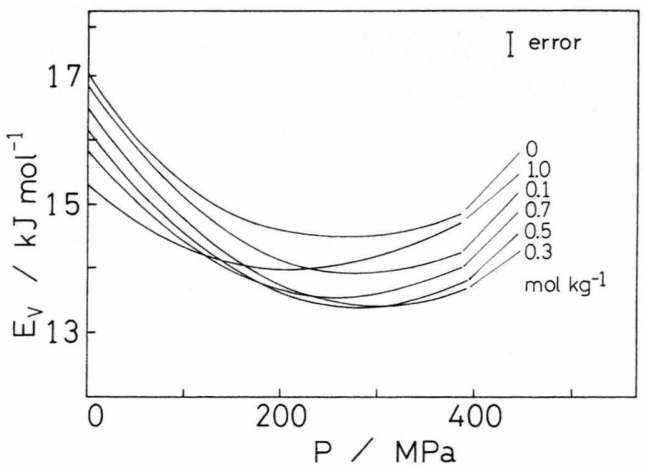

Fig. 3. Pressure dependence of the activation energy for the viscosity of aqueous $\mathrm{NH}_{4} \mathrm{Br}$ solution and water at $298.2 \mathrm{~K}$. 
$E_{\mathrm{v}}$ 's at all concentrations diminish with increasing pressure up to $200-300 \mathrm{MPa}$ and then increase, as similar minimum has been observed for $0-2 \mathrm{~mol} \mathrm{~kg}^{-1}$ $\mathrm{NaCl}$ solution in the same pressure region [4]. The minimum of $E_{\mathrm{v}}$ for water has been ascribed to competition between the decrease of $E_{\mathrm{v}}$ accompanying water-structure breaking by compression and increase of $E_{\mathrm{v}}$ by stuffing of water molecules. The $E_{\mathrm{v}}$ at $0.1 \mathrm{MPa}$ decreases with addition of $\mathrm{NH}_{4} \mathrm{Br}$, as shown in Figure 3. This has been attributed to the water-structure breaking effect of $\mathrm{NH}_{4} \mathrm{Br}$. At high pressure, this effect is thought to become weak because the water structure is already broken by pressure. Therefore $E_{\mathrm{v}}$ at $375 \mathrm{MPa}$ increases with increasing concentration after the reduction from zero to $0.3 \mathrm{~mol} \mathrm{~kg}^{-1}$.

\subsection{Concentration Dependence of the Viscosity}

In Fig. 4 the viscosity is plotted against concentration. Our results at $0.1 \mathrm{MPa}$ and $298.2 \mathrm{~K}$ coincide with the data by Getman [12]. This viscosity at $0.1 \mathrm{MPa}$ decreases with increasing concentration at low temperature between $278.2 \mathrm{~K}$ and $298.2 \mathrm{~K}$. A similar reduction of the viscosity has been observed for several aqueous electrolyte solutions, and at high concentration the viscosity increased, resulting in a minimum [3]. For $\mathrm{NH}_{4} \mathrm{Br}$ solution the minimum is known to be at $2-3 \mathrm{~mol} \mathrm{dm}^{-3}$ [12]. This reduction of the viscosity has been ascribed to breaking of water-structure by addition of electrolyte, and the electrolyte has been classified as a structure breaker [3]. Because the water structure at high temperature is already broken by heat, the viscosity at high temperature does not decrease by addition of the electrolyte, as shown in Figure 4.

With increasing pressure up to $375 \mathrm{MPa}$, the viscosity minimum shifts to low concentrations and appears at $278.2-298.2 \mathrm{~K}$ in Figure 4. This seems to suggest that the water-structure breaking effect of $\mathrm{NH}_{4} \mathrm{Br}$ is weakened by pressure. On the other hand, the slope of the curve at zero concentration at $375 \mathrm{MPa}$ is steeper than that at $0.1 \mathrm{MPa}$, suggesting that the water-structure breaking effect of $\mathrm{NH}_{4} \mathrm{Br}$ is enhanced by pressure. To make the situation clear, it is reasonable to estimate the Jones-Dole's $B$ coefficient [3]. Because the concentration range in Fig. 4 is wide, we use an extended Jones-Dole's equation [13]:

$$
\eta / \eta_{0}=1+A \sqrt{c}+B c+D c^{2}
$$

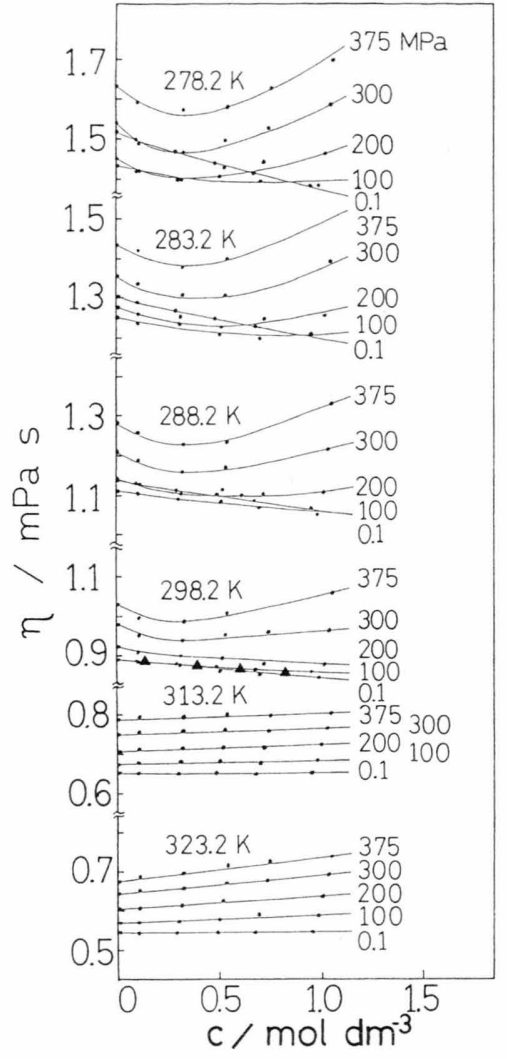

Fig. 4. Concentration dependence of the viscosity for aqueous $\mathrm{NH}_{4} \mathrm{Br}$ solution. $\mathbf{\Delta}$ : Getman [12] at $298.2 \mathrm{~K}$ and $0.1 \mathrm{MPa}$.

where $\eta_{0}$ is the viscosities of water and $c$ is the molarity $\left(\mathrm{mol} \mathrm{dm}^{-3}\right)$ of the electrolytes. This equation can be changed into a linear function of $c$ :

$$
\left(\eta / \eta_{0}-1-A \sqrt{c}\right) / c=B+D c .
$$

The $A$ value can be estimated to be $0.0050 \mathrm{~mol}^{-1 / 2} \mathrm{dm}^{3 / 2}[14,15]$. Its pressure and temperature dependences may be negligible because $A$ itself is small. Therefore we applied this value of $A$ in (7) at all temperatures and pressures. Figure 5 shows linear relations of $\left(\eta / \eta_{0}-1-A \sqrt{c}\right)$ vs. $c$. Our data at $0.1 \mathrm{MPa}$ are in good agreement with those by Getman [12]. The $B$ value at $0.1 \mathrm{MPa}$ is obtained to be $-0.065 \mathrm{~mol}^{-1} \mathrm{dm}^{3}$ by extrapolation of the line to zero concentration. It is compared with $-0.049 \mathrm{~mol}^{-1} \mathrm{dm}^{3}$ calculated from the $B$ values of $\mathrm{NH}_{4}^{+}$and $\mathrm{Br}^{-}$ions by Nightingale [3]. These facts support the validity of our estimation of $B$ using (7). The pressure dependence of the $B$ of $\mathrm{NH}_{4} \mathrm{Br}$ in water is shown in Figure 6. The $B$ 's 


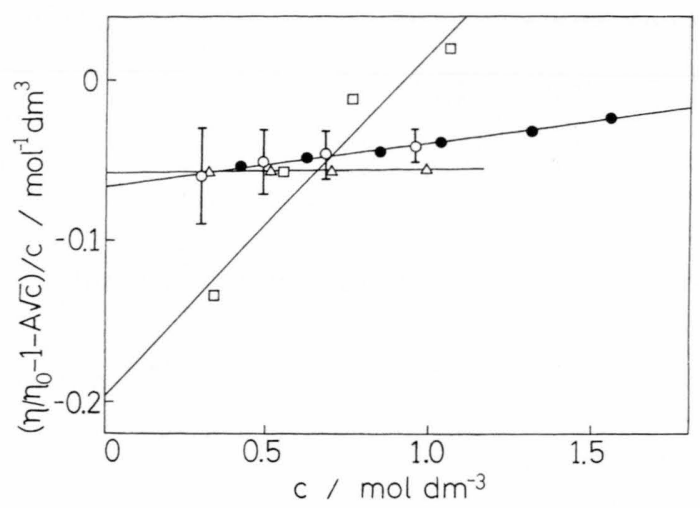

Fig. 5. $\left(\eta / \eta_{0}-1-A \sqrt{c}\right.$ vs. $c$ for aqueous $\mathrm{NH}_{4} \mathrm{Br}$ solution at 298.2 K. ०: $0.1 \mathrm{MPa}, \Delta$ : $100 \mathrm{MPa}$, : $300 \mathrm{MPa}$, •: Getman [12] at $0.1 \mathrm{MPa}$.

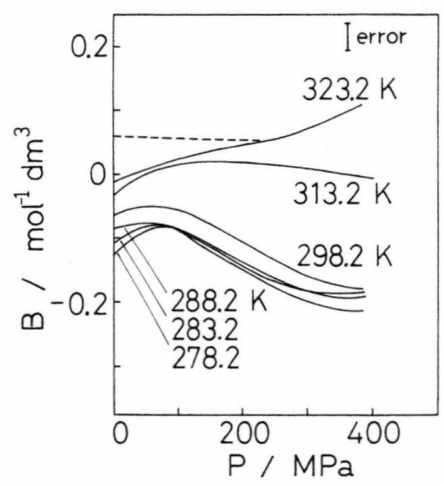

Fig. 6. Pressure dependence of Jones-Dole's $B$ coefficient of $\mathrm{NH}_{4} \mathrm{Br}$ in water. $\cdots \cdots$ : theoretical (see text).

are negative at $0.1 \mathrm{MPa}$, increase with increasing pressure up to ca. $100 \mathrm{MPa}$, and decrease after having a maximum except for the $B$ at $323.2 \mathrm{~K}$. A similar maximum has been observed for $\mathrm{NaCl}$ in water at ca. $100 \mathrm{MPa}$ at 283.2, 298.2, and 323.2 K [4]. The dotted line was estimated by Ibuki and Nakahara's method based on a Hubbard and Onsager's dielectric friction theory [16] using high pressure properties of the viscosity [1], dielectric constant [17], and dielectric relaxation time of water [18]. This line is for elec- trolytes whose ionic radius is $0.1-0.2 \mathrm{~nm}$, including both $\mathrm{NH}_{4} \mathrm{Br}$ and $\mathrm{NaCl}$. It decreases with increasing pressure without any maximum because the theory does not take any water structure into account. The reduction of $B$ for $\mathrm{NaCl}$ with increasing pressure at higher pressure than $100 \mathrm{MPa}$ was ascribed to this effect [4]. On the other hand, the increasing of $B$ for $\mathrm{NaCl}$ up to $100 \mathrm{MPa}$ has been ascribed to an apparent enhancement of $B$ accompanying the structurebreaking in bulk water by pressure [4]. The maximum of $B$ for $\mathrm{NH}_{4} \mathrm{Br}$ in Fig. 6 may be ascribed to competition of these two effects, though the increase of $B$ at $323.2 \mathrm{~K}$ higher pressure than $100 \mathrm{MPa}$ can not be ascribed to these effects, suggesting an other interaction between $\mathrm{NH}_{4} \mathrm{Br}$ and water because this increase has not been observed for $\mathrm{NaCl}$ in water at the same temperature. The matter needs further consideration.

\section{Conclusion}

In the present work, two high-pressure phenomena were observed; (1) the activation energy of viscous flow for aqueous $\mathrm{NH}_{4} \mathrm{Br}$ solution decreases with increasing concentration at $0.1 \mathrm{MPa}$ and increases at high pressure, (2) the Jones-Dole's $B$ coefficient of $\mathrm{NH}_{4} \mathrm{Br}$ in water has a maximum at ca. $100 \mathrm{MPa}$. Similar phenomena have been observed for $\mathrm{NaCl}$ in water [4]. Supposing two types of water, that is, bulk water and hydrated water around an ion, the phenomena are ascribed to breaking of the former structure with increasing pressure, implying that the latter structure does not change (or change less) by pressure. As the hydrated water is strongly attracted by ions, it is reasonable that the structure of hydrated water does not change or change less by pressure than that of bulk water.

\section{Acknowledgements}

Supported by Ritsumeikan Academic Research Grant for Specific Research A. 
[1] International Association for the Properties of Steam, The IAPS formulation 1985 for the Viscosity of Ordinary Water Substance (1984).

[2] E. M. Stanley and R. C. Batten, J. Phys. Chem. 73, 1187 (1969); R. A Horne and D. S. Johonson, J. Phys. Chem. 70, 2182 (1966).

[3] E. R. Nightingale, Chemical Physics of Ionic Solution, John Wiley \& Sons, New York 1966, p. 87.

[4] S. Sawamura, Y. Yoshimura and Y. Taniguchi, J. Phys. Chem. 96, 5526 (1992).

[5] Y. Yoshimura, S. Sawamura, and Y. Taniguchi, J. Soc. Mat. Sci. Japan 42, 1109 (1993).

[6] S. Sawamura, N. Takeuchi, K. Kitamura, and Y. Taniguchi, Rev. Sci. Instrum. 61, 871 (1990).

[7] L. H. Adams, J. Amer. Chem. Soc. 53, 3769 (1931).

[8] Y. Yoshimura, S. Sawamura, J. Matsuda, K. Kitamura, and Y. Taniguchi, J. Soc. Mat. Sci. Japan 41, 318 (1992).

[9] J. H. Dymond and R. Malhotra, Int. J. Thermophys. 9, 941 (1988).
[10] S. Glasstone, K. J. Laidler, and H. Eyring, The Theory of Rate Processes, McGraw-Hill: New York 1941, Chapter 9.

[11] D. Eisenberg and W. Kauzmann, The Structure and Properties of Water, Oxford Univ. Press, Oxford 1969.

[12] F. H. Getman, J. Amer. Chem. Soc. 30, 721 (1908).

[13] D. J. P. Out and J. M. Los, J. Solution Chem. 9, 19 (1980).

[14] H. Falkenhagen and E. L. Vernon, Philos. Mag. 14, 537 (1932).

[15] M. Kaminsky, Discuss. Faraday Soc. 24, 171 (1957).

[16] K. Ibuki and M. Nakahara, J. Chem. Phys. 85, 7312 (1985).

[17] B. B. Owen, R. C. Milner, C. E. Milner, and H. L. Cogan, J. Phys. Chem. 65, 2065 (1961).

[18] R. Pottel, E. Asselborn, and R. Eck, V. Tresp, Ber. Bunsenges. Phys. Chem. 3, 676 (1989). 